Draft copy prior to publication in:

"Expressive and Academic Freedom in Context: Rights, Responsibilities, and Harms," coedited with Shannon Dea, Kennedy Institute of Ethics Journal, 31 (2), June 2021: 133-152.

\title{
The Limits of the Rights to Free Thought and Expression ${ }^{1}$
}

\author{
Barrett Emerick
}

\begin{abstract}
It is often held that people have a moral right to believe and say whatever they want. For instance, one might claim that they have a right to believe racist things as long as they keep those thoughts to themselves. Or, one might claim that they have a right to pursue any scholarly question they want as long as they do so with a civil tone. This paper rejects those claims and argues that no one has such unlimited moral rights. Part 1 explores the value of the freedoms of thought and expression. Part 2 argues against the unlimited moral right to free expression, focusing in particular on the special obligations and moral constraints that obtain for academics. Part 3 argues against the unlimited moral right to free thought.
\end{abstract}

${ }^{1}$ I am grateful for comments from participants at the Canadian Society for Women in Philosophy 2018 conference. Additionally, I am especially grateful to Olivia Bailey, Chris Blocher, Shannon Dea, Kayleigh Doherty, Shane Gronholz, Tyler Hildebrand, Alice MacLachlan, Stephen Masson, Kathryn Norlock, Emily Saari, and Audrey Yap, as well as the editors at KIEJ and two anonymous referees for their invaluable feedback and support. 


\section{Introduction}

In response to the threat of bogeymen like "PC culture" and "the thought police", it is common to hear someone claim that they have a right to think and say whatever they want. ${ }^{2}$ In this paper I'll argue that, when understood as moral rights, those claims are false; no one has the moral right to think or say whatever they want and so if one wants to defend against the bogeymen, one had better look elsewhere.

I will proceed as follows. In Part 1, I will explore the value of the freedoms of thought and expression. In Part 2 I will argue against the unlimited moral right of free expression. In particular, I'll argue that academics bear special responsibility in virtue of their social position and so should interrogate the impacts of their scholarship, whether they are using their social position appropriately, and whether their aims are consistent with achieving justice. In Part 3 I will respond to objections and argue against the unlimited moral right to free thought. In Part 4 I'll conclude. One disclaimer: in this paper I will not assess whether or to what extent the law or any institution should formally constrain anyone's freedom of thought or expression. Instead, I will focus exclusively on the moral right to exercise those freedoms and will argue that even if people ought legally to be free to think or say anything they want, morally, they are not so entitled.

\section{Part 1 - Why Freedom of Thought and Expression are Valuable}

I'll start with some definitions. I'll use freedom of thought to refer to the extent to which people are able to pursue lines of inquiry or maintain sets of beliefs without formal or informal constraint. I'll use freedom of expression to refer to the extent to which people are able to convey to others the data, justifications, or conclusions they reach while exercising freedom of thought without formal or informal constraint.

People have moral rights to exercise those freedoms. I'll use moral rights to refer to entitlements to perform (or refrain from performing) certain actions or to have others perform (or refrain from performing) certain actions. ${ }^{3}$ If someone has a moral right to perform some action that action is permissible. ${ }^{4}$ There is a close connection between impermissibility and blameworthiness such that if someone has a moral right to perform some action others would be wrong to blame them for so acting. For example, if someone has a moral right to use a public bathroom, others would be wrong for blaming them for exercising that right. Conversely, someone does not have a moral right to perform an action that they ought morally not perform (though they might have a legal right to perform such an action - a point to which I'll return in Part 2). For example, if it is wrong for someone to cheat on their romantic partner, they do not have the moral right to do so

\footnotetext{
2 The claim that academics have this right qua academics has been defended in recent papers by Francesca Minerva (Minerva 2014a, 160 and Minerva 2014b, 173) and Robin Barrow (Barrow 2009, 180-181).

3 See "Rights" by Leif Wenar in the Stanford Encyclopedia of Philosophy, which offers what I take to be the standard analysis of the concept. (Wenar 2015)

${ }^{4}$ This is in keeping with Wesley Hohfeld's canonical analysis of privilege rights which says that if someone has a privilege right to perform some action they have no duty not to perform that action. (Hohfeld 1919, 39)
} 
(though they might have the legal right to do so). In other words, no one has a moral right to act wrongly, even if the law allows such actions. ${ }^{5}$

Moral rights are usually constrained in various ways: how, when, where, and to what extent they might be exercised. That someone has a right to do something doesn't mean that right is unlimited. In this paper I'll focus on how far the right to exercise the freedoms of thought and expression extend.

There are at least two reasons why those freedoms are valuable. First, since humans are social knowers and rely on others in their epistemic community not only to test their knowledge claims but to even be able to make knowledge claims in the first place, (Anderson 1995, 189-192) the epistemic community overall will tend to flourish if it is (in general) unconstrained, epistemically diverse, and allowed to be creative. I'll call this the social value of freedom of thought and expression. Second, being a knower is an essential part of being a person and communicating with others is an essential part of being a knower. What follows is that to prevent someone from expressing themself across the board is one method of undermining them as a knower, thwarting their self-fulfillment, and diminishing their personhood. ${ }^{6}$ I'll call this the personal value of freedom of thought and expression. I'll unpack both the social value and the personal value of freedom of thought and expression as I proceed.

I'll start by analyzing the social value. We very often do not know at the outset what lines of thought will bear fruit when combined with the thoughts of others who occupy different social locations, disciplinary backgrounds, or perspectives on the world. Indeed, scientific discovery, the arts, and the humanities flourish precisely when they are exposed to the perspectives of others. But, it's hard (perhaps impossible) to predict in advance when such flourishing will occur. So, all else equal, the best way to promote a flourishing epistemic community is to enable free thought and the expression of that thought, which is generally instrumentally valuable for everyone.

I take this to be what John Stuart Mill was after in On Liberty when he argued that ideas, like seeds, must be given the opportunity to grow in the sunlight of free expression rather than being stifled under oppressive limitations on that expression. ${ }^{7}$ Moreover, if we do not allow such exposure our existing beliefs will wither, becoming "dead dogmas" when unchallenged in the marketplace of ideas, and with them the intellectual life of the larger epistemic community. (Mill 2008, 22)

\footnotetext{
${ }^{5}$ Some have argued that one can have a right to act wrongly. I won't delve into that literature except to say that I do not deny that there might be times where one does not have a privilege right to commit some action but does have a claim right not to have others prevent them from committing that action. So, for example, your coworker does not have a privilege right to cheat on their partner but they do have a claim right to not have you interfere and prevent them from doing so. In that way they might be said to have a right to act wrongly. I take it, however, that most people who would claim the unlimited rights to free thought and expression against which I'm arguing would think that they not only have those rights but that they do nothing wrong in exercising them. I take that to be the standard view against which I'm arguing.

${ }^{6}$ This is tied to what is sometimes presented as "the autonomy defense" of the legal right to free expression. For more on this, see Brison 1998a and 1999 and Heldke 1991.

${ }^{7}$ For a helpful discussion of Mill's position and many related issues, see Heldke 1991.
} 
I used to be a Millian. ${ }^{8}$ I wish I could be, now; it's such a romantic view of intellectual community; such an attractive vision of how social knowing would go if left to run its course. Sadly, such an idealistic vision does not perceive the world clearly, nor any epistemic community that I'd wager has ever been. The reason why is that, precisely because we do not know things in isolation from each other but instead do so socially, and because the social world is shot through with power relations that affect what gets heard, who gets heard, and how we should interpret what is said, the liberal idea that the court of public opinion could ever judge fairly, dispassionately, and without bias now seems to me hopelessly naïve. Because of background power relations that are embedded in and born from social relations, allowing all arguments to see the light of day will not in fact promote a flourishing epistemic community. (Anderson 1995, 202) Those power relations cannot be accounted for or eliminated through mere procedural changes to the way the marketplace of ideas functions; the problem will not be solved by encouraging everyone simply to speak to each other civilly or by policing the tone of those who speak. ${ }^{9}$ The reason why is that even when said with a polite tone, the very expression of some beliefs within a backdrop of injustice itself causes harms that have the effect not only of undermining the personal value of free thought and expression, but the social value as well. (Jaggar 2007, 162) For instance, there is no way to question whether some groups are inferior, deviant, or "the Other" without employing uncivil aggression, since what is said and not just how it is said is itself seriously harmful, a point to which I'll now turn.

\section{Part 2 - Limits to the Right to Free Expression}

There are a variety of harms that someone might suffer as a result of what others express. ${ }^{10}$ I will focus on four of them here.

First, someone's reputation or social status can be harmed as a result of what others say about them or those who share their social identity. (Brison 1999, 285; Brison 2005, 241) That loss of status can have many seriously deleterious effects, including making it harder to find work, to secure good housing and medical care, and to make it more likely that they are subjected to physical violence. For instance, if prominent politicians employ racist dog-whistles to communicate that black people are prone to criminality, it is no surprise when each of those negative effects become more likely for black people as a social group, regardless of whether any particular black person breaks any laws.

Second, even if someone doesn't suffer those material harms, having others say disparaging or disrespectful things about them might still subject them to harms of moral offense. It's easy to dismiss harms of offense as those experienced only by oversensitive people who simply ought to toughen up or have thicker skin. It's also a serious mistake to do so. As profoundly social

\footnotetext{
${ }^{8}$ To be clear: Mill did not defend the claim that there should be no restrictions on expression. But, he did argue that, as a practical matter, allowing rather than restricting expression is always instrumentally valuable. It is this claim with which I no longer agree. Many cite Mill approvingly, appealing to the instrumental value of free expression. See for instance: Scanlon 1972 and Singer 1992.

9 Each of these authors offers some version of this prescription: Singer 1992, Barrow 2009, Dworkin 1996, Mill 2008.

${ }^{10}$ For more on this, see Brison $1998 \mathrm{~b}$
} 
beings, we are impacted essentially by the appraisal of others. ${ }^{11}$ When someone fails to recognize another's value as a person, it is reasonable and appropriate to feel deeply hurt. (That's not to say that someone ought to feel hurt, nor that someone always will, but just that if someone encounters such disrespect, it is not an overreaction to experience such injury.) So, what I'll refer to as the harm of moral offense moves beyond surface level matters of discourtesy and to the more fundamental type of moral disregard one displays for another by questioning, for instance, whether they are fully rational, naturally disposed towards criminal behavior, or have less moral value than others. One secondary harm of moral offense is that it expresses clearly that someone does not belong in certain spaces, professions, relationships, or institutions, and so can serve as a barrier of entry for each. (Heldke 1991, 359; Anderson 1995, 201-202)

Third, consider the phenomenon of stereotype threat, in which people come to underperform at various tasks that common stereotypes suggest they would be unlikely to excel. If someone knows that the social expectation is that "people like them" do badly when trying to perform some action, that knowledge can cause them to perform more poorly than they would if they were not worrying about accidentally fulfilling the stereotype. In that way the stereotype becomes a self-fulfilling prophecy, since they have generated what will be taken to be additional evidence to its adherents that the stereotype is true.

Fourth, consider the phenomenon of epistemic injustice, which is to be "wronged in one's capacity as a knower." (Fricker 2007, 44) Specifically, consider testimonial injustice, in which one is attributed less credibility than is warranted due to one's social identity. When subjected to reiterated instances of such wrongs over time (or in some important one-off moments) the victim of epistemic injustice might be diminished in their epistemic capacities as a giver or receiver of knowledge, at least with regard to certain types of knowledge. (Fricker 52-54; Heldke 1991, 361)

In what follows I will refer to the four harms just outlined as exclusionary harms because they can cause, in addition to devastating personal effects, the exclusion of those harmed individuals from participating in and contributing to the larger epistemic community. ${ }^{12}$ That outcome is easily foreseeable. When stereotypes or beliefs held in the social imaginary claim that certain social groups are bad in one way or another, it is disingenuous to feign surprise when those exclusionary harms follow. This is true not only as a result of those background beliefs held in the social imaginary, but when particular prominent individuals make such claims (as indicated with the racist-dog-whistling politician mentioned above).

Imagine, for instance, that a scholar (let's call him Charles) claims that black people are genetically inferior to white people. Charles is taken relatively seriously by academia, at least enough to be invited regularly to give public lectures on college campuses. Charles' lecture on a particular campus might cause the following harms: 1. It might cause black students to be less likely to be able to join an academic community (because they're less likely to be admitted to

11 Feminist philosophers in particular have developed the claim that humans are essentially relational. See, for instance: Lindemann 2014 and Brison 1999 among many others. Lisa Heldke also argues that we should understand free speech to be limited in virtue of the fact that, as relational beings, what others say affects (either positively or negatively) who we become. Heldke 1991, 356-357.

${ }^{12}$ What I am calling exclusionary harms are different from incitement of violence or hate speech. Though it is easy to pay lip service to caring about the personal cost of exclusionary harms, in practice they are not taken very seriously. For examples see: Barrow 2009, Singer 1992, Minerva 2014a, Dworkin 1996. 
graduate school or hired in an academic job) because of reputational harms. 2. It might cause black students to be less likely to want to join such a community because of moral offense. 3. It might cause black junior scholars to be less likely to perform well when they try to join such a community because of stereotype threat. 4. It might result in black scholars suffering testimonial injustice (being assigned lower levels of credibility in virtue of their social group membership) once they manage to do so.

Each of those harms constitutes a violation of both the personal and social value of free thought and expression. As I said at the outset, at least three features of a flourishing epistemic community are their tendency toward innovation, discovery of the truth, and creation. All else equal, an epistemic community that fails to be innovative and creative in its thinking is less likely to discover new things about the world than one that is. One of the ways that we can promote innovation and creativity in an epistemic community is by promoting diversity of perspective; as Mill so eloquently argues, to make sure our beliefs don't become dead dogmas we should ensure they are open to challenge from new quarters which thereby disrupt group-think and the sameness of observation and interpretation that homogeneity of observers tends to produce. And, as standpoint epistemologists have argued, it's not just that epistemic communities need diverse knowers to flourish, they need certain perspectives in particular that are better situated to perceive and interpret parts of the world than others. ${ }^{13}$ Specifically, when considering parts of the social world, oppressed people are (in general) more likely to recognize and understand oppression than are privileged people, since the view from the bottom is more likely to be complete and less distorted than the view from the top. ${ }^{14}$

In short, to promote a flourishing epistemic community we need to make sure that it is inclusive, especially of oppressed perspectives. That inclusion becomes all the more important for the promotion of the social value of free thought - when the line of inquiry an epistemic community pursues involves oppression or injustice. So, returning to Charles' research: if the scientific community is studying the relationship between race and genetics, it's important (for the purpose of producing better research) that it not be populated only by white scholars. Since the exclusionary harms I outlined above serve as barriers of entry to epistemic communities, and since those harms can be caused by pursuing lines of inquiry like those Charles pursues, far from promoting the underlying social value of free thought, asking those questions undermines it.

Summing up: the reason why the right to free expression is not unlimited is that if it were, it would enable exclusionary harms and thereby render the epistemic community worse off. Not only would the personal value of free expression be undermined (for those individual scholars who suffer harms of exclusion), the social value would itself would be undermined, since that exclusion would make the epistemic community less diverse. Indeed, Mill's whole point is that we have better conversations in the public square, have better beliefs to trade in the marketplace of

${ }^{13}$ Much has been written about standpoint epistemology. For two especially helpful places to start, see Harding 1992 and Jaggar 1983, Chapter 11. However, as Elizabeth Anderson notes, one need not even embrace full-fledged standpoint epistemology in order to make the claim that one's social location is relevant to what one will experience and be justified in believing. Anderson 1995, 197. ${ }^{14}$ That's not to say that people who occupy an oppressed social location will necessarily occupy a superior epistemic location, nor does it imply that those who occupy a privileged social location can't adopt the superior standpoint of the oppressed. (They can and should!) It is instead simply to say that there is considerable epistemic value to ensuring a diverse epistemic community. For more on this, see Harding 1992, 456-457 in particular. 
ideas, when there are lots of options to choose from. (Heldke 1991, 354) But, letting anyone trade any ideas at all can have the net effect of putting some traders out of business. ${ }^{15}$ In that way interpreting the freedom of expression as unlimited undermines what makes that freedom valuable in the first place. ${ }^{16}$ As a result, everyone has an obligation to be mindful of the ways in which what they say could cause exclusionary harms and shouldn't say such things without good reason.

One might reply that it's often not so easy to know when such harms will follow, nor is it always so easy to know what counts as "a good reason", and that it is only via the free exchange of ideas that we will be able to make such determinations. How can we know in every case whether we have a good reason to make certain arguments?

I won't settle that question here, and there might be some lines of inquiry for which that question will be impossible to answer. Fortunately, there are some cases in which we do have good reason at hand and in which we are justified in thinking that by pursuing certain lines of inquiry as an open matter we cause exclusionary harms to vulnerable groups of knowers. For instance, if someone chooses to research the relationship between race and genetics, given the long history of racist science that precedes their work, they run a higher risk of causing exclusionary harms than someone who chooses to study quasars. In general, if a scholar's area of research is relevant to the life chances of oppressed people, it becomes more foreseeable that their research could cause or contribute to the harms of exclusion I described above. In those cases where it seems possible that someone would cause exclusionary harm to others by pursuing certain lines of inquiry, they have good reason to do so with special care, or not to do so at all.

What about cases where those harms are harder to foresee? Or, where someone could have foreseen those harms but failed to avoid causing them? In those cases where exclusionary harms follow from the scholar's inquiry, they have the duty to try to repair the harms that they cause (at least by working to publicly counteract the claims they made in their earlier research). Some areas of research run more of a risk of generating such reparative obligations than others. Part of what comes along with morally risky behavior are the potential reparative obligations someone might bear should those risks prove costly. If a scholar doesn't want to have to do that reparative work, they should pursue a different line of research where such obligations are less likely.

One might object that this holds scholars to too high a standard. After all, as long as Charles sticks to the scientific method in asking the questions he finds interesting (and for which he can secure funding), he should be free to publish (and publicize) any results he generates along the way.$^{17}$ In other words, the objection says that we should simply let the scientific method do its job, attempt to filter out subjective bias, and reveal objectively true things about the world.

15 This is what Anderson calls a "systemic market failure". Anderson 1995, 202.

${ }^{16}$ Minerva claims that "Research is, among other things, about challenging common sense, testing the soundness of ideas that are widely accepted as part of received wisdom, or because they are held by the majority of people, or by people in power. The proper task of an academic is to strive to be free and unbiased, and we must eliminate pressures that impede this." Minerva 2014a, 160. The trouble, as Anderson 1995 argues and as I have tried to show, is that accomplishing that goal within a backdrop of injustice actually requires that some things not be said in order to create space for others to join the conversation. A failure to create that space leaves existing, dominant views of the day unchallenged, thereby undermining Minerva's stated goal. See also Jaggar 2007.

${ }^{17}$ For instance, Barrow claims that, "It is essential that we get back to the academic imperative. The academy is founded on a belief in truth and reason, and its purpose is to uphold and spread understanding... While courtesy is desirable and encouragement useful, we are not here to be 
One problem with this claim is that scholars don't merely gather and report data; they also choose the methods by which they gather and interpret it, as well as which questions to ask in the first place. All three choices create opportunities for the purity of the data to become infected by background ideologies that reflect and perpetuate existing social norms. ${ }^{18}$ Feminist philosophers of science and feminist epistemologists have demonstrated time and again the ways in which that's the case, and as a result, the fact/value distinction, or a bright line between the descriptive and the normative, is simply untenable. (Yap 2016; Jaggar 1987; Anderson 2004) I won't rehearse all those arguments here, except to focus on the last place where ideology sneaks its way into the supposedly hermetically sealed laboratory or research space: which questions scholars choose to ask (and which projects receive funding) in the first place. Why ask whether one racial group is more likely to be violent, whether there is a "math gene" that makes one gender more likely to be better at math, or whether humans are "by nature" selfish? What value comes in answering those questions, and what cost comes with asking them?

To be clear, I am not offering a thorough account of how to determine which studies ought to be performed; perhaps there is some value to asking those three questions. My point instead is that we should reject the claim that the choice simply to pursue one line of research rather than another, or to ask one set of questions or entertain one hypothesis rather than another, is morally or politically neutral. Quite the opposite, in a world shot through with injustice, pursuing any question that has to do with social reality cannot possibly be neutral. (Jaggar 1987, 38) Far from it: by choosing to ask one question rather than another, by choosing to dignify one hypothesis for testing rather than another, scholars contribute their considerable social status towards legitimizing from the beginning the claim being investigated and are therefore at least partially responsible for the exclusionary harms such investigations produce.

In addition to the standard epistemic responsibilities that everyone bears, academics in particular bear special epistemic obligations born from the role they play in society. (Teichman 1994, 104) If someone has a $\mathrm{PhD}$ or holds a research position at a university, in general their voice is likely to carry more weight than if they do not. So, when Charles is invited to speak at a college campus about the ways in which black people are genetically inferior to white people, his talk is potentially harmful in ways that one given by a local member of the Ku Klux Klan might not be. The Klansman can be written off as a racist (though of course his talk would likely be hugely offensive); Charles cannot be dismissed so easily. After all, he carries with him the trappings of scholarship and of being an expert. When he speaks he does so with the veneer of respectability, using terms and appealing to theories and studies that many in the audience might not be wellpositioned to understand or dismiss. Since scholars carry that additional epistemic status they also carry the potential to do more damage than non-scholars when they say things that cause exclusionary harms. And, since an agent's degree of responsibility is at least informed by how much of an impact their actions are likely to cause, scholars have special obligations that go beyond those borne by many outside the academy.

It is ironic, then, that those who enjoy academic freedom have the most responsibility to exercise their legal right to free expression carefully, and in some cases, to refrain from exercising it at all. Even if an idea seems plausible to a scholar, or a question interesting, they ought to exercise

polite at all costs, to help level society, to ensure a supply of workers for the economy, or to make people feel good. We are here to search and argue for what we have reason to believe is true." Barrow 2009, 189. See also Singer 1992 and Dworkin 1996, 189-190.

${ }^{18}$ For good examples of this, see: Martin 1991; Okruhlik 1994. 
special caution in pursuing it if they could reasonably anticipate that doing so might cause the kinds of harms I've described throughout. That doesn't mean that in every case they ought to refrain from pursuing the potentially problematic line of inquiry (though they ought to be careful about how they pursue it). Sometimes, however, the responsible scholar will recognize that even if their hypothesis is correct, and even if they are not themselves prejudiced, within unjust social structures and within oppressive ideological climates, some questions ought to be left unasked.

\section{Part 3 - Limits to the Right to Free Thought}

That concludes my positive argument against the unlimited right of free expression. I believe it is actually not as controversial as it initially might seem, despite the fact that it is common to believe that the moral right to say whatever you want is inalienable and unlimited. Or rather, that's what people believe they believe, though I don't think that most people actually endorse such a strong view. Most people believe that doctors should preserve doctor-patient confidentiality, that children should be taught not to say unnecessarily hurtful things, and that someone ought not lie to others without good reason. But, each of those are cases in which it is morally impermissible (wrong) to say one thing rather than another. And, no one has a moral right to act wrongly. Why the controversy?

I believe it can be traced at least in part to the fact that it is easy to conflate legal rights with moral rights. In the United States the Constitution guarantees citizens the right to free speech - the right not to be punished by the government for expressing themselves however they like - at least for the most part (though there have always been limitations on just what that right entails). But, legal rights are not the same thing as moral rights, and the fact that a citizen has a legal right to do something tells us nothing about whether they have a moral right to do it. Again, consider that someone cheating on their romantic partner is doing something morally impermissible (and so they do not have a moral right to do so). That doesn't commit us to the conclusion that the state ought to punish anyone for infidelity. Indeed, we might well value privacy and the state's staying out of such personal affairs. It is not inconsistent to think that infidelity should be legal despite being immoral. Cutting in the other direction, some actions should be illegal that are not morally impermissible. (Driving one mile over the speed limit breaks the law but is not immoral.)

That point - that moral rights do not ensure legal rights (and vice versa) - is one to which it's easy to pay mere lip service. Most people would agree that legal and moral rights are not necessarily the same - most people would agree that someone doesn't have a moral right to infidelity while acknowledging that whether the state sanctions it is an entirely different question. But, when pressed, people often appeal to the fact that they have a legal right to commit an action as justification for the fact that they have a moral right to perform that action, and of course that's just not true. So, within the U.S. context in particular, it's common to appeal to the First Amendment as justification for what seems to be the moral right to express oneself however they like. But, the one does not ensure the other and we often ought morally to avoid committing actions that are legally permitted.

Perhaps what causes people to overestimate their own commitment not only to the freedom of expression but also of thought is that they are worried in particular about being punished for exercising those freedoms. (That might explain what people are worried about when they suspect the Thought Police are going to knock down their door.) Who has the power to punish? Narrowly, I take it that the state has the power to intentionally aim to make someone worse off because they have broken the law. More broadly, I take it that others in one's community might punish someone 
(intentionally aim to make them worse off) because they have violated some formal or informal norm.

All these worries are reasonable - we all have good reason to worry about the state punishing anyone, and social norms can be devastating to individuals and whole social groups when enforced via punishment. But the fact that the threat of punishment is real doesn't mean that the freedoms of thought and expression are limitless. Note again that I am here entirely setting aside the question of whether the state should ever police thought and expression; again, I'm exploring whether anyone has an unlimited moral right to think and say whatever they'd like and leaving the legal/political question for another time. Social punishment is another matter. Here someone might appeal to the unlimited right to free expression in order to defend themself in advance against the criticism or censure they would experience socially. (Minerva 2014a, 161; Barrow 2009, 188.) Indeed, if they have a moral right to commit an action, and others act retributively as if they have acted wrongly (trying to punish them for doing so), that punishment is misplaced since to have a moral right to commit an action entails that it's permissible to do so.

This concern is met by noting that the fact that someone doesn't have a moral right to do something doesn't mean that anyone else has a moral right to punish them for doing so. They may or they may not: that remains an open question about which we'd need to know more about a particular case. At the least we'd need to talk about others' standing to interfere in the life of another, as well as to inflict foreseeable harm on them. In short, the fact that social punishment for a moral wrong can be excessive or entirely inappropriate doesn't mean that the action being punished wasn't wrong; instead, in such a case those enacting the punishment themselves commit an additional wrong. Again, this is not very controversial. Many people think that cheating is wrong, but when they learn of a coworker's infidelity they also believe it would be wrong to take it upon themselves to punish the perpetrators.

Perhaps the worry is different and instead of a concern about being punished what motivates the conflation is a worry simply about being harmed (by which I just mean "made worse off") by others as a result of their exercise of the legal rights to free thought and expression. There are, after all, a number of harms one might suffer as a result of speaking one's mind. Here are some of them:

- Harm 1 - One might lose their job;

- Harm 2 - One might be regarded negatively by others;

- Harm 3 - One might lose relationships (both actual and potential).

Note the distinction here between punishment and the infliction of foreseeable (but non-punitive) harm. I take it that when someone aims to punish another they aim to make them worse off precisely because it makes them worse off, either because they believe it's deserved, or to discourage others from doing the same thing, or because they believe doing so in some way rights the wrong. (Boonin 2008) That means that whether someone is punished is determined in part by the aim of the actor doing the harming.

Take Harm 1: if I fire an employee who was embezzling from my company, I might do so because I think they deserve to be made worse off, or I might do so because I no longer trust them to do their job. If the former, I've punished them. If the latter, I have not. Now imagine that my accountant announces that they've discovered a new form of mathematics that lets them run the numbers much more quickly. After demonstrating their new method many times, and after reaching the wrong conclusion many times, I start to doubt their ability to do math. If I fire them I have harmed them but I have not punished them. My reason for doing so is that I can't trust them 
to do their job well because they hold mistaken beliefs about how mathematics works. I am foreseeably making them worse off because of beliefs that they hold and what those beliefs imply about their ability to do their job effectively.

Now consider Harms 2 and 3. Let's say you go out on a date with someone who reveals halfway through dinner that they are a member of the flat-earth society and a big believer in what you take to be various conspiracies. At the end of the night they ask for a second date and you decline (as you aren't interested in arguing or hearing about how the earth is flat or the moon landing wasn't real). They are very sad about this - they really like you - and this contributes to their significantly diminished self-esteem (they've had a run of bad luck with love). You foreseeably make them worse off by declining to date them because of their beliefs, but you also do nothing wrong in so declining.

Perhaps my critic would reply that in both of these cases what we're dealing with are facts and not values; there's an objective fact of the matter about how to balance the books and it's important for a business owner to get the right answer at the end of the day. And, there's an objective fact of the matter about whether the earth is flat or whether the moon landing was a hoax; those things have been confirmed by multiple sources and our epistemic warrant for both is quite high. Since it's reasonable to want to date someone who responds rationally to evidence, it's not wrong to decline a second date with the conspiracy theorist. But things are very different (the objection goes) when we're talking about social or moral matters.

As an example: imagine that your workplace is on average, politically liberal. A few conservative colleagues complain that they are treated unfairly for their beliefs. "This isn't right," they exclaim after a meeting one day. "All of you are punishing us for being conservatives whereas you are all liberals! We feel ostracized, not really a part of the community, just for holding the beliefs that we do. But you know what? We have a right to say and think whatever we want and shouldn't be punished as a result!" They would likely go on to grant that, if they were flat-earthers and you didn't want to be friends with them, that would be one thing (since that would be evidence of their irrationality). But, it's wrong of you to harm them in that way - to withhold friendship or a warm reception in the community - when the beliefs in question are normative rather than descriptive.

Despite their understandable desire to feel welcome and included, I suspect the conservatives in the case are unlikely to actually believe that someone should never suffer any harm because of their beliefs. Imagine that, on your first date with someone, instead of discovering that they believe the earth is flat, they believe that the tragedy of the Holocaust was that it didn't kill more people. You do nothing wrong by declining a second date, even if doing so foreseeably harms them in the ways that I mentioned above. But, of course that's a matter of values and the conservatives in question would likely agree that you act permissibly. We can make things even more clear by going on to add that not only do you decline a second date, you tell your friends about the whole encounter. Word gets around (it being a small community) and eventually no one wants to date them. At this point their self-esteem plummets, they suffer the real and significant harm of loneliness, and their overall welfare is much lower than it once was - all because of the beliefs they hold. Again, it seems unlikely that your conservative colleagues would say that anyone is wronged because of their beliefs (even though those beliefs are about values rather than facts). But, at that point, they've given up the game, since they've granted that beliefs about values are a morally justifiable reason to refrain from spending time with someone. The difference seems to be one of degree rather than kind. Consider these two propositions: 
"Judaism is bad and should be eliminated."

And

"State-run social welfare programs are bad should be eliminated."

The first is widely acknowledged to be abhorrent and so it is reasonable to want not to be friends with someone who believes it. The structure of the two beliefs is the same, the recommendation the same. So, it's a mistake to conclude that you wrong a libertarian by withholding friendship from them in virtue of the fact that they hold beliefs about values with which you disagree.

Now, there might well be other moral reasons that count in favor of not writing them off. General duties of beneficence might require that you treat someone whose views you find repugnant kindly, or duties of justice might require that you work to try to change their mind rather than disengaging from them. I won't argue for either claim here. My point instead is simply that the conservatives' objection that they are wronged by being left friendless and regarded negatively simply because of their beliefs about values - because they have a right to believe whatever they want - is false, and if it is the case that they're owed more, it's not because they have a right to free thought.

Their belief is false for two reasons. To restate the first: the moral rights to free thought and expression do not always make it wrong to foreseeably harm someone because of their beliefs; whatever the moral rights to free thought and expression entail they do not entail that, nor the broader claim that they have a right not to be foreseeably harmed by others because of their beliefs. The second is that they don't in fact have a moral right to believe whatever they want, which is the point to which I'll now turn. In short, it's just not true that anyone may permissibly believe anything at all and so the right to free thought is not without limit.

Although this might seem like a controversial claim, on the contrary, I think it's not actually very controversial at all. Consider the Christian commandment that you should love your neighbor as yourself. You cannot be said to genuinely love someone and believe them to be utterly contemptable at the same time. You might have conflicted feelings about them, but if someone were to claim that they love their neighbor as they love themselves, and then say that they believe members of their neighbor's racial group have no more value than a pile of garbage, you'd be right to question their sincerity. In short: the very common Western claim that we ought to love everyone in virtue of their being children of God entails certain beliefs and precludes others. And, since a great many people think that you ought to do what Christianity commands, I contend that a great many people in fact believe that morality governs their beliefs - or at least some of them. And, when push comes to shove, a great many people believe that their commitment to Christianity trumps their commitment to other beliefs that they hold. What follows is that a great many people reject the absolute and unconstrained moral right to free thought, even though they believe they do otherwise. This argument doesn't apply only to Christianity, but to any religious tradition that emphasizes that we ought to adopt a respectful regard for other people, which entails and precludes holding certain beliefs about them. Since all such religions combined have a great many adherents, it turns out not to be very controversial at all to think that we don't in fact have an unconstrained moral right to free thought.

So, the widespread belief that everyone has a right to believe whatever they like is in tension with other also very widespread beliefs, many of which are at least equally as foundational for those who hold them. I am not claiming that the fact that those beliefs are widespread is 
evidence for their truth. But, it does seem to me that the religious views I've just described are on to something. It seems morally basic that you ought not hate someone, view them as trash, as offal, regard them as something utterly without value, without good reason to do so. You should not, for instance, hate someone because of the color of their skin, or their gender, or their nationality, and regard them as having no more value than a bit of dirt to be scraped off your shoe. And, not regarding someone in that way entails not believing those things about others. Since those types of prejudicial regarding are wrong, so is that type of prejudicial believing.

This quick argument won't convince everyone. But, I think that enough people will agree that those types of racism, sexism, and xenophobia are abhorrent so that the point is worth making anyway, since if they think that they are then committed to rejecting the claim that everyone has an unlimited right to believe whatever they like, and that's no small conclusion.

\section{Part 4 - Conclusion}

I have argued that the rights to the freedom of thought and expression are not absolute or unrestrained; there are real limits to which epistemically responsible actors ought to hold themselves. That conclusion obtains even more strongly for scholars whose special social status as experts makes their exercise of those rights all the more potentially perilous. I have also argued that the reasons why we should care about having those freedoms - what I have called the social and personal values of both - are better served by our judiciousness in their exercise. Part of what this discussion encourages us to face is the question of whose freedoms of thought and expression matter. It is easy to say that those freedoms should be absolute and universal, and perhaps in a future, utopian world everyone will be able to exercise those freedoms without causing the exclusionary harms I have explored here. But we do not live in such a world, and one implication of living within a backdrop of injustice it that the expression of some thoughts causes serious harm to others. If someone puts their foot down and simply asserts that their rights to free thought and expression are absolute, they must also be prepared to admit that their freedoms matter more than others' (since their exercise of those freedoms undermines the ability of others to do the same). ${ }^{19}$

What I have not done in this paper is assess what the legal limits of either right ought to be. Whether the state, or any powerful institution, ought to punish someone for their beliefs or words is a difficult question - and it is one I have set entirely to the side throughout. Indeed, my project has been much more modest. In focusing on the moral rather than the legal question, it was my goal to show that even if it's a good thing legally to be free to think or say whatever we want, morally, we ought not do so. Given that conversations about legal limits often rely on the possession of those moral rights, it is my hope that this paper can be helpful in making those conversations more productive.

${ }^{19}$ See Anderson 1995 who aims to untangle this knot. 


\section{WORKS CITED}

Anderson, Elizabeth. 1995. "The Democratic University: The Role of Justice in the Production of Knowledge." Social Philosophy and Policy, 12: 186-219.

----- 2004. "Uses of Value Judgments in Science: A General Argument, with Lessons from a Case Study of Feminist Research on Divorce." Hypatia, 19(1): 1-24.

Barrow, Robin. 2009. “Academic Freedom: Its Nature, Extent and Value.” British Journal of Educational Studies, 57 (2): 178-190.

Boonin, David. 2008. The Problem of Punishment. New York: Cambridge University Press.

Brison, Susan. 1998a. “The Autonomy Defense of Free Speech” Ethics, 108(2): 312-338

----- 1998b. "Speech, Harm, and the Mind-Body Problem in First Amendment Jurisprudence" Legal Theory 4 (1): 39-61

----- 1999. "Relational Autonomy and Freedom of Expression" in Catriona Mackenzie and Natalie Stoljar, eds. Relational Autonomy: Feminist Perspectives on Autonomy, Agency and the Social Self, New York: Oxford University Press: 280-299

---- 2005. “"The Price We Pay'? Pornography and Harm.” in Andrew I. Cohen and Christopher Heath Wellman, eds., Contemporary Debates in Applied Ethics, Oxford: Blackwell: 236-250

Dworkin, Ronald. 1996. "We Need a New Interpretation of Academic Freedom." in Louis Menand, ed., The Future of Academic Freedom, Chicago: The University of Chicago Press: 187198.

Fricker, Miranda. 2007. Epistemic Injustice: Power and the Ethics of Knowing. Oxford University Press.

Harding, Sandra. 1992. "Rethinking Standpoint Epistemology: What is "Strong Objectivity?". The Centennial Review, 36, No. 3: 437-470.

Heldke, Lisa. 1991. "Do You Mind if I Speak Freely? Reconceptualizing Freedom of Speech." Social Theory and Practice, 17, No. 3.

Hohfeld, Wesley. 1919. Fundamental Legal Conceptions As Applied in Judicial Reasoning and Other Legal Essays. New Haven, CT, USA: Yale University Press.

Jaggar, Alison. 1983. Feminist Politics and Human Nature. Lanham, MD, USA: Rowman and Littlefield.

---- 1987. "Sex Inequality and Bias in Sex Difference Research." The Canadian Journal of Philosophy, 13 (supplement): 25-39. 
----- 2007. “Teaching in Colorado: Not a Rocky Mountain High; Academic Freedom in a Climate of Repression." Teaching Philosophy, 30 (2): 149-172.

Lindemann, Hilde. 2014. Holding and Letting Go: The Social Practice of Personal Identities. New York: Oxford University Press.

Martin, Emily. 1991. "The Egg and the Sperm: How Science Has Constructed a Romance Based on Stereotypical Male-Female Roles." Signs: Journal of Women in Culture and Society, 16 (3): 485-501.

Mill, John Stuart On Liberty. 2008. In the version by Jonathan Bennett presented at www.earlymoderntexts.com

Minerva, Francesca. 2014a. "New Threats to Academic Freedom.” Bioethics, 28 (4): 157-162.

----- 2014b. "Why Publishing Pseudonymously Can Protect Academic Freedom.” Bioethics, 28 (4): 178-180.

Okruhlik, Kathleen. 1994. "Gender and the Biological Sciences." The Canadian Journal of Philosophy, 20: 21-42.

Scanlon, Thomas. 1972. “A Theory of Freedom of Expression.” Philosophy \& Public Affairs, 1 (2): 204-226.

Singer, Peter. 1992. "A German Attack on Applied Ethics: A Statement by Peter Singer." Journal of Applied Philosophy, 9 (1): 85-91.

Teichman, Jenny. 1994. "Freedom of Speech and the Public Platform." Journal of Applied Philosophy, 11 (1): 99-105.

Wenar, Leif. 2015. "Rights," The Stanford Encyclopedia of Philosophy, Edward N. Zalta (ed.), $\mathrm{URL}=\underline{\text { https://plato.stanford.edu/archives/fall2015/entries/rights/ }}$

Yap, Audrey. 2016. "Feminist Radical Empiricism, Values, and Evidence." Hypatia, 31 (1): 5873. 